\title{
Corrigendum to "Climatologies of subtropical mixing derived from 3D models" published in Atmos. Chem. Phys., 3, 1007-1021, 2003
}

V. Eyring ${ }^{1}$, M. Dameris ${ }^{1}$, V. Grewe ${ }^{1}$, I. Langbein ${ }^{2}$, and W. Kouker ${ }^{2}$

${ }^{1}$ DLR Institut für Physik der Atmosphäre, Oberpfaffenhofen, D-82234 Wessling, Germany

${ }^{2}$ Forschungszentrum Karlsruhe, Institut für Meteorologie und Klimaforschung, 76344 Eggenstein-Leopoldshafen, Germany

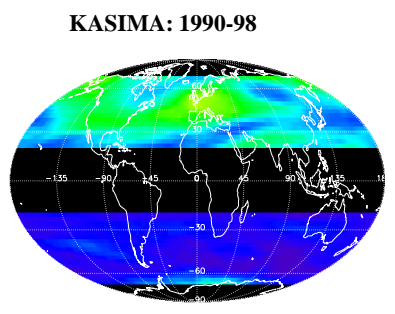

DJF
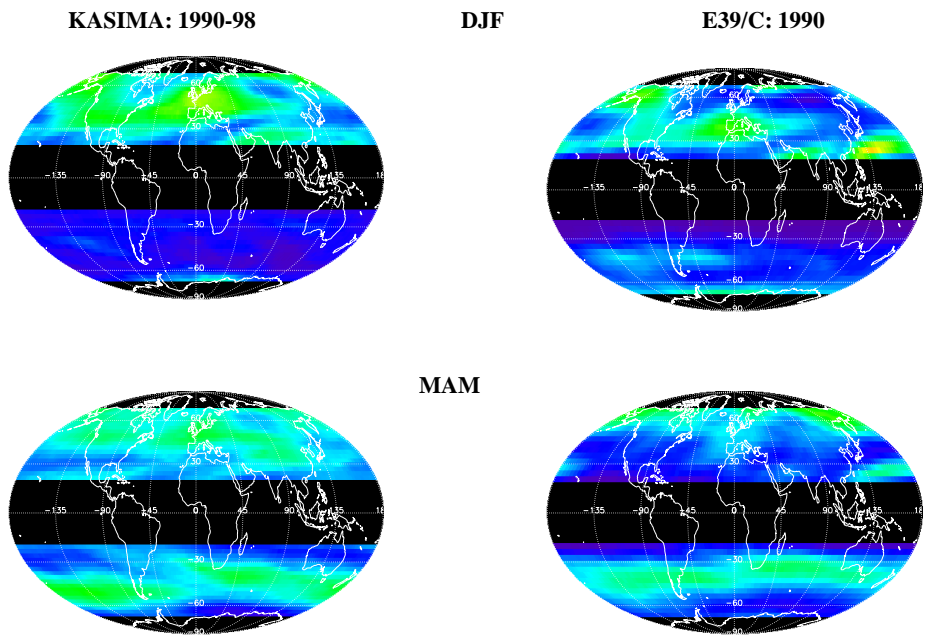

MAM

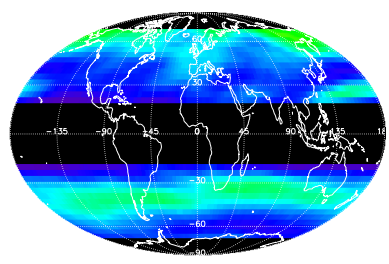

JJA
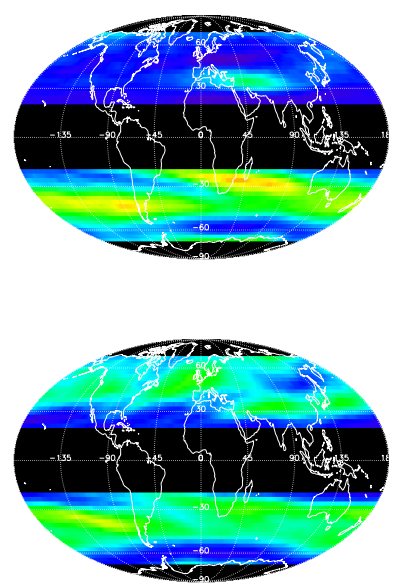

SON
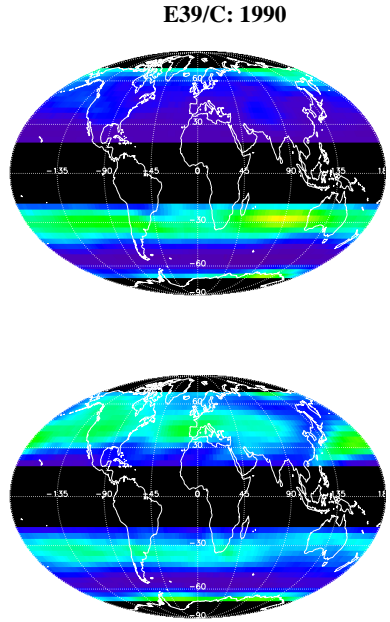

Comparison of KASIMA (left side) and E39/C (right side) streamer-climatologies averaged between 21 and $25 \mathrm{~km}$ for different seasons. From top to bottom: DJF, MAM, JJA, SON-season.

Correspondence to: V. Eyring

(Veronika.Eyring@dlr.de)

(C) 2005 Author(s). This work is licensed under a Creative Commons License. 